\title{
Architecture of Tools of Estimating the Influence of Renewable Sources on the Electricity Cost in Ukraine
}

\author{
H. A. Ivanov ${ }^{1}$, I. V. Blinov ${ }^{2 *}$, E. V. Parus ${ }^{2}$ \\ ${ }^{1}$ State Company “ Guaranteed buyer ” Kyiv, Ukraine. \\ ${ }^{2}$ Institute of Electrodynamics National Academy of Science of Ukraine, Kyiv, Ukraine. \\ *Corresponding author. E-mail: blinovihor@gmail.com
}

Paper received 25.11.20; Accepted for publication 15.12.20.

\author{
https://doi.org/10.31174/SEND-NT2020-244VIII30-12
}

Abstract. Aspects of supporting the development of renewable energy sources (RES) producers in Ukraine are analyzed. Aspects of the Guaranteed Buyer's work, its interaction with other participants of the electricity market are considered. It is shown that one of the methods to solve the problems related to increase in the share of RES is the need to analyze the components of the influence of supply by RES stations on the market value of electricity, and the framework of simulation modeling system architecture, as well as the main functions of calculating the cost of electricity being formed on the market are determined.

Keywords: renewable electricity sources, guaranteed buyer, electricity market, simulation model.

Introduction. In pursuance of the Law "On the Electricity Market" [1] a new electricity market has been operating in Ukraine from July 1, 2019. The market model defined by the Law corresponds to the generally accepted European model [2] and meets the requirements of the third energy package. At the same time, the national electricity markets of European countries implement the additional use of various mechanisms to stimulate or support market participants within the implementation of certain national programs. Thus, in 2009, Ukraine undertook legally guaranteed obligations to purchase all electricity [3] supplied by renewable energy source (RES) stations at a feed-in tariff until 2030. The main components of these obligations include: purchasing electricity supplied by RES at a fixed feed-in tariff; purchasing electricity by a centralized stateowned enterprise; timely payments for purchased electricity. Thus, the new market model includes the functions of a fundamentally new participant in the electricity market, i. e. a Guaranteed Buyer (GB) [4]. This market participant should purchase at a feed-in tariff all electricity from RES in full and implement the mechanisms provided by law to compensate for such a tariff. In view of this, as well as the rapid increase in the share of RES in the overall balance of the IPS in Ukraine, the urgent task that needs to be addressed at present is to build models and tools for estimating the influence of RES on the market value of electricity in Ukraine taking into account the applicable legislation requirements, technological limitations of RES functioning and processes in the electricity market.

The share of RES in electricity generation in Ukraine have increased from $3.4 \%$ in 2019 to $7.9 \%$ for the three quarters of 2020. At the same time, the share of provision by coal-fired TPPs and CHPs have decreased from $37 \%$ in 2019 to $32.4 \%$ for three quarters of 2020 . In spite of a number of advantages, the increase in the share of RES in the balance of IPS capacities in Ukraine has exacerbated a number of both technological and financial problems. Technological problems include the regulation of the IPS in Ukraine under the conditions of the increased share of RES, which are characterized by unregulated poorly predicted change in the levels of electricity production. At the same time, the increase of requirements for the volume of reserves for the regulation of IPS regimes in Ukraine applies not only to the operational frequency regulation for the ancillary services market (ASM), but also to balancing electricity production/consumption in the balancing market (BM).

The influence of RES on pricing processes is more ambiguous. The increase in the volume of electricity from RES stations mandatory for sale results in the displacement of the most expensive coal-fired power plants and in lower prices on a day-ahead market (DAM). The decreased prices in the DAM segment, in turn, stimulate the decrease in BM prices. In contrast, the increased share of RES in Ukraine's IPS results in an increase in the volume and cost of both ancillary services and imbalances. The increase in the volume of provisions for the needs of DAM and BM causes a reduction in the available supply in the DAM segment and as a result overall increase in prices in this market segment.

The biggest economic problem of increasing the share of RES in the structure of production capacities of the IPS in Ukraine became the problem of payments for electricity supplied by RES at preferential feed-in tariffs. Thus, with the introduction of a liberalized model of the electricity market in Ukraine in the summer of 2019, the compensation of tariffs for electricity supplied by RES was actually carried out at the expense of hydro and nuclear power plants (HPPs and NPPs). Accordingly, the GB purchased electricity from HPPs and NPPs at fixed low prices at specialized auctions of the market of bilateral contracts and resold the purchased volumes in the DAM segment at market prices. The benefit was used to compensate for feed-in and other preferential tariffs. However, this source of preferential tariff coverage has been exhausted due to the interrelated significant increase in electricity demand to compensate for preferential tariffs and a significant drop in prices in the DAM segment. At the same time, the tariff of a Transmission System Operator does not provide for a sufficient share of funds to cover all costs, which has resulted in the accumulation of debts of the Transmission System Operator to the GB in 2020. For the GB, in turn, debts to HPPs, NPPs and RES producers have accumulated. The permission granted to the GB in the fall of 2020 to sell the forecast volumes of electricity from RES stations somewhat reduces the problem of working capital lack, but does not solve the problem of debt accumulation in general. In this case, in order to determine the amount of coverage of preferential tariffs for RES producers from the tariff of the Transmission System Operator, it is necessary, in turn, to forecast the amount of funds to be covered by the resources 
provided to the Guaranteed Buyer. Thus, in order to make economically sound management decisions, it is necessary to develop tools for forecasting electricity supply by RES stations and modeling pricing functions in market segments to simulate the actions of the Guaranteed Buyer in market segments and calculate the economic results of such actions.

Analysis of Recent Sources of Research and Publications. At present, the world has accumulated considerable experience in modeling electricity markets, theoretical and practical methods for solving problems of modeling the electricity market are being developed, research on the organization and functioning of new models of electricity markets, for example, [5,6] is being carried out. It should be noted that the scientific and practical principles of introduction of different components of the liberalized electricity market [7-12] created in Ukraine, developed methods and models for solving problems of optimizing operation of power systems, providing ancillary services [13] in the market conditions, forecasting of prices, and forecasting of electricity supply by RES producers $[14,15]$ do not completely solve the problems of complex modeling of this market, in particular work of the GB as a party responsible for the balances of RES producers, which does not allow to perform accurate calculations of prices and electricity purchase and sale volumes in all market segments and prices for the final consumer.

Purpose and Objectives of Research are to determine the basic requirements and architecture of tools of comprehensive estimation of the influence of electricity production by RES stations on the components of the cost of electricity for the final consumer.

Formulation of the Problem. In order to adequately estimate the amount of resources required for tariffs for RES electricity producers to be covered, it is necessary to solve the following main tasks:

- developing methods and tools for forecasting the supply of electricity by RES stations and estimating the volume of imbalances allowed;

- developing methods and tools for estimating the influence of electricity supply from RES stations on the cost of electricity in organized market segments and on the tariff for the final buyer.

The influence of RES electricity producing plants on prices and tariffs should be determined by a comparative analysis of the results of the functioning of the electricity market of Ukraine without and with participation of such production facilities. Comparisons of options with different volumes of electricity production by RES facilities should be made using the values of electricity costs calculated for these options for the final consumer.

In order to determine the basic requirements for the structure and tools of calculating prices and tariffs, the features of interaction of the GB with other participants in the electricity market have to be considered (Fig. 1).

The Guaranteed Buyer receives from the RES production stations the forecasts of electricity production based on which it generates the aggregate schedule of the offer on the DAM. Further the Guaranteed Buyer buys/sells electricity on the intraday market (IDM) for the purpose of reducing imbalances. Based on the results of the BM operation, imbalance prices are formed and the Settlement Operator generates an invoice for the payment of imbalance prices for the GB balancing group. Based on the results of financial calculations, the GB pays the cost of electricity supplied to RES stations.

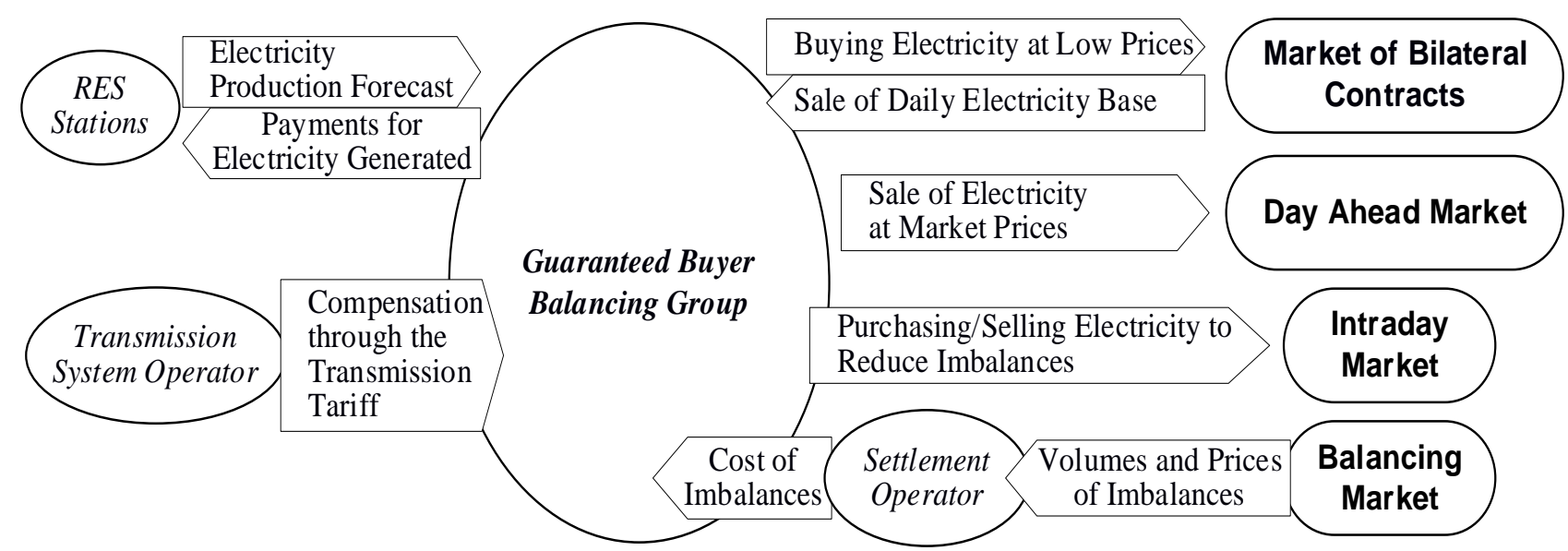

Fig. 1 The main components of the Guaranteed Buyer's interaction with other participants in the electricity market

Thus, for modeling aimed at estimating the economic consequences of the GB's activities in the electricity market, it is necessary to implement the following main components of the software tools:

- tools for forecasting electricity supply by RES stations for different time intervals;

- tools for simulation modeling of pricing processes in individual market segments to estimate the influence of RES on the cost of electricity;
- tools for simulation of individual functions of the business model of the Guaranteed Buyer for calculations of electricity cost for the final consumer.

Fundamentals of simulation modeling system architecture. The calculations of the influence of individual influence factors of RES stations on prices in market segments are based on the interaction of software tools for the forecasting RES electricity production and software tools for modeling pricing functions in segments of the electricity market of Ukraine (Fig. 2). 


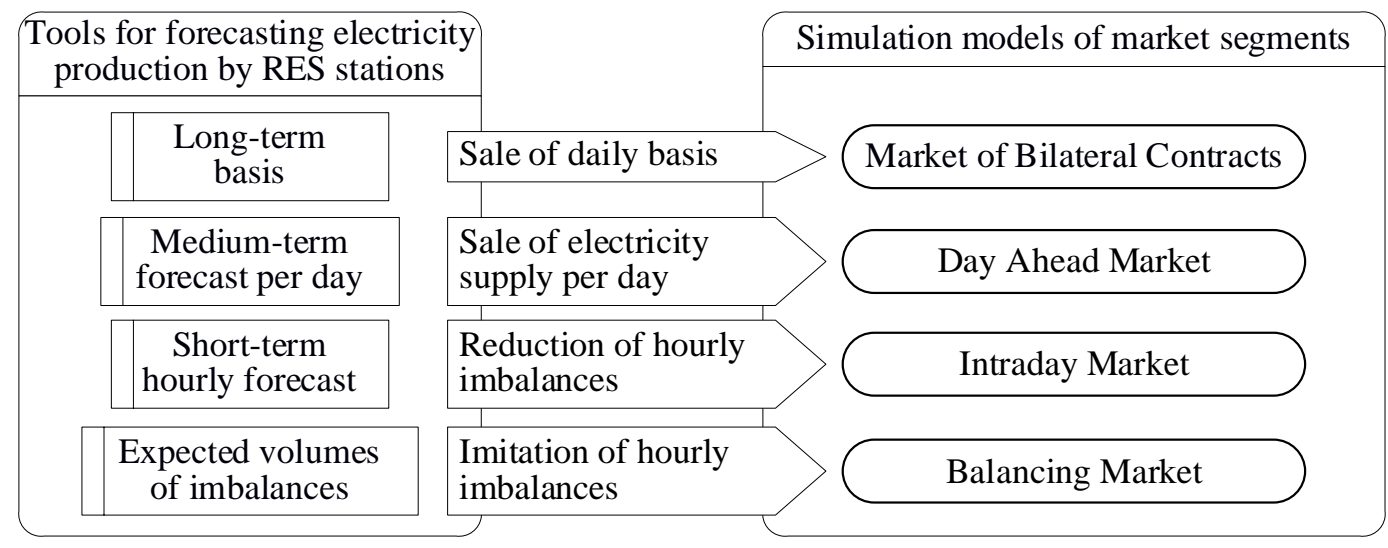

Fig. 2 The main functions of calculating the components of the electricity cost

Forecasting tools calculate the volume of electricity production by RES stations for different periods of time for use by appropriate models of simulation of pricing functions of individual market segments. Thus, the long-term forecast per month is used to model the transaction of sale of the basic level of electricity supply in the segment of bilateral contracts. The medium-term forecast for a few days in advance is used to form a daily schedule of hourly volumes of electricity supply in order to simulate the pricing functions in the DAM segment. The short-term forecast of hourly volumes of electricity supply by RES stations a few hours before the hour of sale is used to estimate the feasibility of reducing imbalances by purchasing/selling electricity at intraday auctions. Finally, based on the results of solving forecasting problems, the quality of forecasts is estimated, confidence intervals are determined and probable volumes of imbalances are calculated for simulation modeling of pricing functions in the balancing market.

The results of price calculations in individual market segments are used to solve a number of problems, for example, estimating the influence of electricity production by RES stations on the market component of electricity cost, or calculating the amount of additional funds needed to settle with producers at reduced tariffs (Fig. 3).

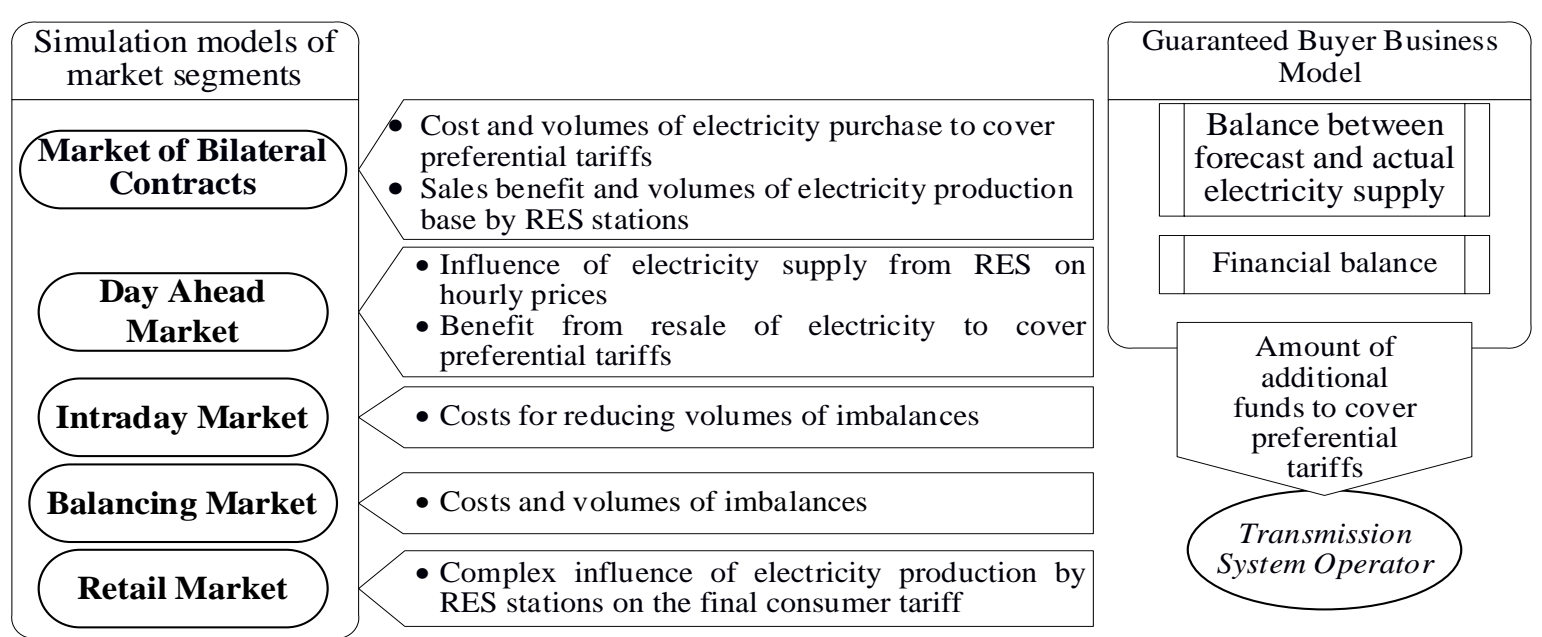

Fig. 3. The main functions of estimating the RES influence on the cost of electricity

A separate software unit uses the tools of simulation modeling of pricing functions of individual segments of the electricity market in order to generate a balance of purchase/sale of electricity. Taking into account the results of the GB operation, the balance of purchase/sale of electricity is generated, which corresponds to the balance of electricity production/consumption. The received balance is used to generate an economic balance. Volumes of the received economic balance (or volumes of economic imbalance) represent numerous decisions of the set tasks, as consequences of realization of individual functions of the GP business model.

Conclusions. Analysis of the organization of the electricity market functioning and the interaction of the GB with other market participants demonstrated that in general the GB mechanism implements government obligations to investors in feed-in energy and effectively plays the role of a party responsible for imbalances of RES producers. According to the results of the analysis of the components of influence of the RES proposal on the pricing processes, the complex and ambiguous nature of this influence is noted. From the list of methods for solving the problems associated with increase in the share of RES, the need to analyze the components of influence of supply by RES stations on the market price of electricity is highlighted and the basics of the simulation modeling system architecture, as well as the main functions of calculating the electricity cost components are identified, and their practical implementation will allow for creating the effective tooling to prepare sound management decisions for addressing problems related to the progression of RES problems. 


\section{REFERENCES}

1. On Electricyty Market: The Law of Ukraine. 13.04.2017 No 2019-VIII.

2. Ivanov H., Blinov I., Parus Ye. Simulation Model of New Electricity Market in Ukraine// 2019 IEEE 6th International Conference on Energy Smart Systems (ESS). 2019. Pp. 339342

3. On Alternative Energy Sources: The Law of Ukraine. 20.02.2003. № 555- IV.

4. Ivanov H.A., Blinov I.V., Parus E.V., Miroshnyk V.O. Components of model for analysis of influence of renewables on the electricity market price in Ukraine. Technical Electrodynamics, 2020, No 4, Pp. 72-75

5. Lin J., Magnago F. Electricity Markets: Theories and Applications// IEEE Press Series on Power. 2017. p.p. 352

6. Momoh J., Mili L. Economic Market Design and Planning for Electric Power Systems// Istitute of Electrical and Electronics Engineers. 2009. p.p. 277. DOI:10.1002/9780470529164

7. Kyrylenko O.V., Blinov I.V., Parus E.V., Ivanov G.A. Simulation model of the day-ahead electricity market with implicit consideration of network limitations of energy systems. Tekhnichna elektrodynamika. 2019. No 5. Pp. 60-67. (Ukr) DOI: https://doi.org/10.15407/techned2019.05.060

8. Blinov I.V., Parus E.V. Congestion management and minimization of price difference between coupled electricity markets. Tekhnichna elektrodynamika. 2015. No 5. Pp. 81 - 88. (Ukr)

9. Saukh S.; Borysenko A. Representation of Transmission and Distribution Networks in the Mathematical Model of the Electricity Market Equilibrium// 2019 IEEE 20th International Conference on Computational Problems of Electrical
Engineering

(CPEE).

2019. doi: 10.1109/CPEE47179.2019.8949116

10. Zamulko A.; Veremiichuk Y; Mahnitko A. Assessment of potential electricity demand aggregation at ukrainian electricity market //IEEE 7th International Conference on Energy Smart Systems (ESS). 2020. DOI: $10.1109 /$ ESS50319.2020.9160194

11. Zhuikov V, Pichkalov I, Boyko I, Blinov I. Price formation in the energy markets of Ukraine// IEEE. Electronics and Nanotechnology (ELNANO). 2015 IEEE 35th International Conference on. DOI: 10.1109/ELNANO.2015.7146953

12. Ostapchenko K.B., Lisovychenko O.I., Borukaiev Z.Kh. Regulatory Mechanism Model to Stimulate Companies in the Single Buyer Wholesale Market// Èlektron. model. 2019. 41(6):37-48

13. Blinov I., Parus E. Approach of Reactive Power Pricing for Ancillary Service of Voltage Control in Ukraine. Intelligent Energy and Power Systems (IEPS), 2014 IEEE International Conference on. 2014. P. $145-148$.

14. Blinov I.V., Miroshnyk V.O., Shimanyuk P.V. Short-term interval forecast of the total supply of electricity by producers from renewable energy sources. Pratsi Instytutu Elektrodynamiky Natsionalnoi Akademii Nauk Ukrainy. 2019. Issue 54. Pp. 5-12. (Ukr)

15. Kulyk M., Zgurovets O. Modeling of Power Systems with Wind, Solar Power Plants and Energy Storage. Part of the Studies in Systems, Decision and Control book series (SSDC, volume 298), 2020. p. 231-245. Springer, Cham. https://doi.org/10.1007/978-3-030-48583-2_15 